\title{
SILICA-CAST REPLICAS FOR MORPHOLOGY STUDIES ON SPRUCE AND BIRCH XYLEM
}

\author{
Per Valdemar Persson ${ }^{1}$, Andrew Fogden ${ }^{1, \dagger}$, Jonas Hafrén ${ }^{2}$, \\ Geoffrey Daniel ${ }^{2}$ \& Tommy Iversen 1 ,*
}

\begin{abstract}
SUMMARY
Sol-gel mineralization has been used and evaluated as a tool for morphological studies on Picea abies and Betula verrucosa. Wood specimens and a pulped spruce sample were impregnated with a silica sol-gel and subsequently heated (calcined) to condense the surfactant-templated polysilicic acid into structured mesoporous silica. During this calcination process, the wood substance and the surfactant were removed and a silica-cast replica of the sample was obtained. The sol-gel mineralization method produced replicas that were studied by environmental scanning and transmission electron microscopy (ESEM, TEM) without additional sample preparation. The calcination induced some shrinkage above the fiber level, but the ultrastructural dimensions were not discernibly affected. The silica-cast replica method may therefore be a useful tool for studies of the wood ultrastructure, including the cell-wall pore structure (microcavities), down to the nanometer level.
\end{abstract}

Key words: Birch, pulp, silica-cast replica, sol-gel mineralization, spruce, wood morphology.

\section{INTRODUCTION}

To fully understand the mechanical and physical properties of wood, the ultrastructural arrangement of the fiber wall needs to be understood. Electron microscopy is a versatile tool often used to study this type of structured biomaterial. Cast replica is a method that has been successfully used in the study of wood structure. Sodium metasilicate (Drum 1968), silicon elastomer (André 1998), low-density polyethylene (Fujii \& Hatano 2000), styrene (Fujii 1993; Kitin et al. 2001) and, more recently, silica zeolite (Dong et al. 2002) are examples of casting media that have been used for making wood replicas. These replicas are produced by impregnation followed by polymerization, hardening or curing. The cell-wall material is then degraded and removed, chemically or thermally. The casts produced using these methods are often imprints of the cell lumina and they provide general structural information about cell-wall surfaces. In the present study, a

1) STFI, Swedish Pulp and Paper Research Institute, Box 5604, SE-114 86 Stockholm, Sweden.

2) SLU, Swedish University of Agricultural Sciences, WURC, Department of Wood Science, Box 7008, SE-750 07 Uppsala, Sweden.

$\dagger$ †) Present affiliation: YKI, Institute for Surface Chemistry, Box 5607, SE-114 86 Stockholm, Sweden.

*) Corresponding author [E-mail: tommy.iversen@stfi.se]. 
method based on a sol-gel as casting medium (Shin et al. 2001) has been implemented and tested with regard to its applicability for morphological studies on spruce and birch wood. This sol-gel, based on polysilicic acid (Iler 1979), penetrates the walls of the wood cells and subsequently condenses. The organic material is then degraded and vaporized by thermal treatment (calcination), during which a transformation into porous silica takes place. This hierarchically structured silica can be observed by electron microscopy without further sample preparation. Research on biomorphous inorganic materials and wood-inorganic composites has traditionally been aimed at the development of new materials with tailored properties (Saka et al. 1992; Ota et al. 1995; Davis et al. 1997; Mann et al. 1997; Greil et al. 1998; Ogasawara et al. 2000). Although the sol-gel mineralization method has previously been shown to successfully produce high-resolution cast-replicas of wood (Shin et al. 2001), to the authors' knowledge this technique has not previously been used as a tool specifically for morphological studies on wood. In this paper the cell-wall structure, including microcavities, in spruce and birch wood has been studied, particularly the three-dimensional structure of xylem by environmental scanning electron microscopy (ESEM) and the detailed structure of a pit by transmission electron microscopy (TEM). A kraft pulp was also studied using TEM to demonstrate the usefulness of the method for studies of the porous structure of the cell wall down to the nanometer level.

\section{MATERIALS AND METHODS}

\section{Preparation of silica sol-gel}

A method slightly modified from that developed by Shin et al. (2001) was used for the preparation of the silica sol-gel. Hexadecyltrimethylammonium chloride (CTAC, $3.7 \mathrm{~g}$ ) was dissolved in $11 \mathrm{ml}$ ethanol $(99.5 \%)$ and $1.8 \mathrm{ml} \mathrm{HCl}(\mathrm{aq}, 1.39 \mathrm{M})$. After the addition of $10 \mathrm{ml}$ tetraethyl orthosilicate (TEOS, 98\%), a stable dispersion of polysilicic acid was formed. The reaction generated heat $\left(40-50^{\circ} \mathrm{C}\right)$, and the product was cooled to room temperature prior to use. Teflon vessels were used for all TEOS-containing mixtures.

\section{Kraft pulping of spruce wood}

Wood chips from spruce (Picea abies, $5 \mathrm{~g}$, dry weight) were mixed with kraft cooking liquor. The cooking liquor was prepared by mixing $134 \mathrm{ml}$ of a stock solution of $\mathrm{NaOH}(\mathrm{aq}, 1.81 \mathrm{M}$ ) and $\mathrm{NaSH}(\mathrm{aq}, 1.64 \mathrm{M}$ ) with $16.1 \mathrm{ml} \mathrm{NaOH}$ (aq, 9.79 M). The total sodium concentration was then adjusted to $2.4 \mathrm{M}$ by the addition of $104 \mathrm{~g} \mathrm{NaCl}$. Finally, water was added to a volume of 1 liter. The [HS-] and $\left[\mathrm{OH}^{-}\right]$of the resulting cooking liquor were $0.22 \mathrm{M}$ and $0.4 \mathrm{M}$, respectively. The liquor-to-wood ratio (w/w) during pulping was $20: 1$. Reduced pressure (45 min) was applied in order to remove air. The wood chips, placed in a steel bomb, were then heated in an oil bath at a rate of $1{ }^{\circ} \mathrm{C} / \mathrm{min}$ starting at $70^{\circ} \mathrm{C}$. When the temperature had reached $140^{\circ} \mathrm{C}$, the black liquor was removed and replaced with fresh cooking liquor. The temperature was then increased by $1{ }^{\circ} \mathrm{C} / \mathrm{min}$ to $170^{\circ} \mathrm{C}$ and maintained at this temperature for $190 \mathrm{~min}$. The bomb was removed from the bath and cooled rapidly in an ice bath. The pulp chips were finally 
washed thoroughly with an excess of deionized water. A residual lignin content of $3 \%$ (corresponding to kappa number 18) was determined by titration with potassium permanganate according to the standard test method ISO 302-1981 (ISO 1998).

\section{Preparation of silica-cast replicas}

Industrially produced wood chips ( $1 \mathrm{~g}$, approx. $20 \times 10 \times 5 \mathrm{~mm}$ ) of spruce (Picea abies) and birch (Betula verrucosa) were first soaked in $50 \mathrm{ml}$ ethanol (95\%) and then placed under vacuum for $30 \mathrm{~min}$ to remove air and to facilitate impregnation. After $24 \mathrm{~h}$, the solvent was changed to an equal volume of $99.5 \%$ ethanol, and the chips were placed under vacuum (30 min) and thereafter left for an additional 24 hours. The pulp sample, which was not allowed to dry after the cooking process, was treated similarly. The wood and pulp chips were then immersed in the sol-gel mixture (see above) and kept at $60^{\circ} \mathrm{C}$. After 3 days, the impregnated chips were removed and air-dried before being heated at $575^{\circ} \mathrm{C}$ for $6 \mathrm{~h}$ in air, for calcination and removal of organic material.

\section{Electron microscopy}

The silica-cast replicas were studied by environmental scanning electron microscopy (ESEM) and transmission electron microscopy (TEM). ESEM images were taken using a Electroscan ESEM 2020 at an acceleration voltage of 10-15 kV. TEM observations were made using a Philips CM12, at an acceleration voltage of $60 \mathrm{kV}$. The brittleness of the silica-cast replicas meant that they could be fractured into fragments suitable for TEM observation.

\section{Monosaccharide analysis}

The relative contents of neutral monosaccharides in untreated and sol-gel-impregnated wood and pulp samples were determined. The samples were hydrolyzed by sulfuric acid, reduced by potassium borohydride and derivatized, using acetic anhydride and 1-methylimidazole, into alditol acetates, according to the method of Theander and Westerlund (1986). The monosaccharides were determined by injecting the samples on an anion exchange chromatograph in combination with pulsed amperometric detection (Hardy et al. 1988).

\section{RESULTS AND DISCUSSION}

\section{Impregnation of the wood cell wall}

The microcavities of the cell wall have been extensively investigated using methods such as NMR (Li et al. 1993), solute exclusion (Stone \& Scallan 1968; Scallan 1987) or size determination of metal crystals present in the wall (Frey-Wyssling 1937; FreyWyssling \& Mitrakos 1959). These studies indicate microcavities in the wood cell wall of the order of 3-30 $\mathrm{nm}$ in diameter. Penetration of the cell wall by polysilicic acid is feasible using the method of this study (Shin et al. 2001). The surfactant (in this study, CTAC) serves as a directing agent and a template during impregnation (Mann et al. 1997) and facilitates the polymerization of the silica (Monnier et al. 1993). Shin et al. (2001) concluded that the presence of CTAC is crucial for the successful large-scale impregnation of wood and they proposed a mechanism for the mineralization process, 
in which the polysilicic acid preferably condenses around the polar (hydroxyl) groups of the cell-wall polymers.

Analysis of the relative monosaccharide content (Table 1) of the untreated and impregnated samples showed only small differences between the impregnated and untreated wood and pulp samples. This indicates that no major chemical degradation of any specific carbohydrate takes place in the wood or pulp samples during the sol-gel impregnation.

Table 1. The relative content of neutral monosaccharides in impregnated and untreated wood and pulp samples. Trace: less than $0.4 \%$.

\begin{tabular}{lcccc}
\hline & \multicolumn{3}{c}{ Relative amount of neutral monosaccharides (\%) } \\
\cline { 2 - 5 } & $\begin{array}{c}\text { Impregnated } \\
\text { wood }\end{array}$ & $\begin{array}{c}\text { Untreated } \\
\text { wood }\end{array}$ & $\begin{array}{c}\text { Impregnated } \\
\text { pulp }\end{array}$ & $\begin{array}{c}\text { Untreated } \\
\text { pulp }\end{array}$ \\
\hline Arabinose & trace & 1 & trace & trace \\
Galactose & 5 & 2 & trace & trace \\
Glucose & 69 & 67 & 87 & 86 \\
Xylose & 9 & 9 & 7 & 7 \\
Mannose & 17 & 21 & 6 & 7 \\
\hline Total & $\mathbf{1 0 0}$ & $\mathbf{1 0 0}$ & $\mathbf{1 0 0}$ & $\mathbf{1 0 0}$ \\
\hline
\end{tabular}

\section{Silica-cast replicas of wood}

The replication technique presented here provides a visualization of the cell-wall ultrastructure. It was possible to observe the cell-wall casts directly by electron microscopy without further sample preparation. Figure 1 shows samples from different stages of the impregnation process. The structure on the macroscopic level of the calcined

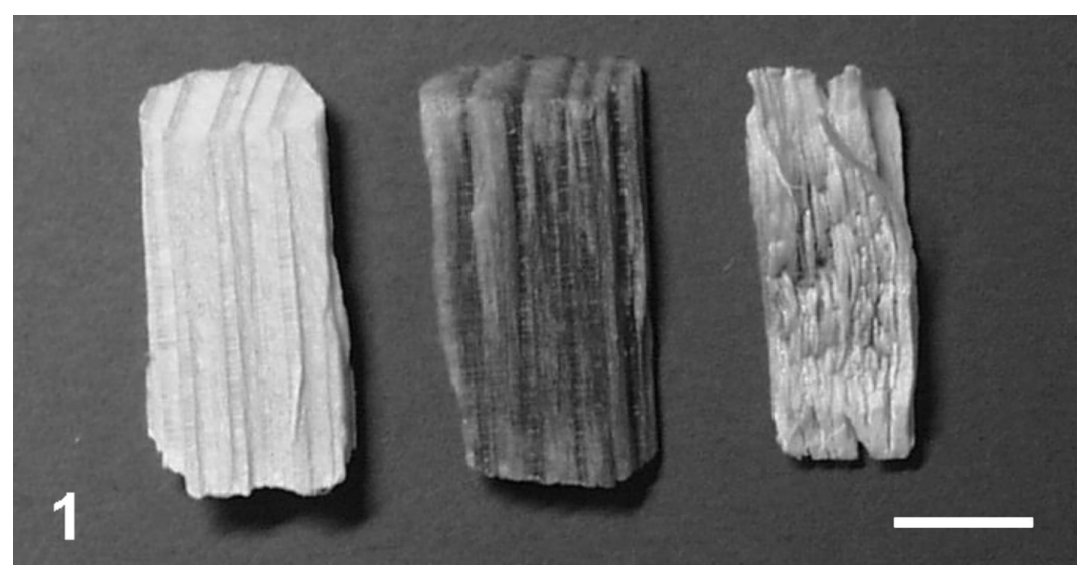

Fig. 1. Preparation of silica casts from spruce wood (different chips of equal size). Left: Untreated wood. Center: Silica-mineralized wood. Right: Silica cast after calcination and removal of all organic material. - Scale bar $=1 \mathrm{~cm}$. 

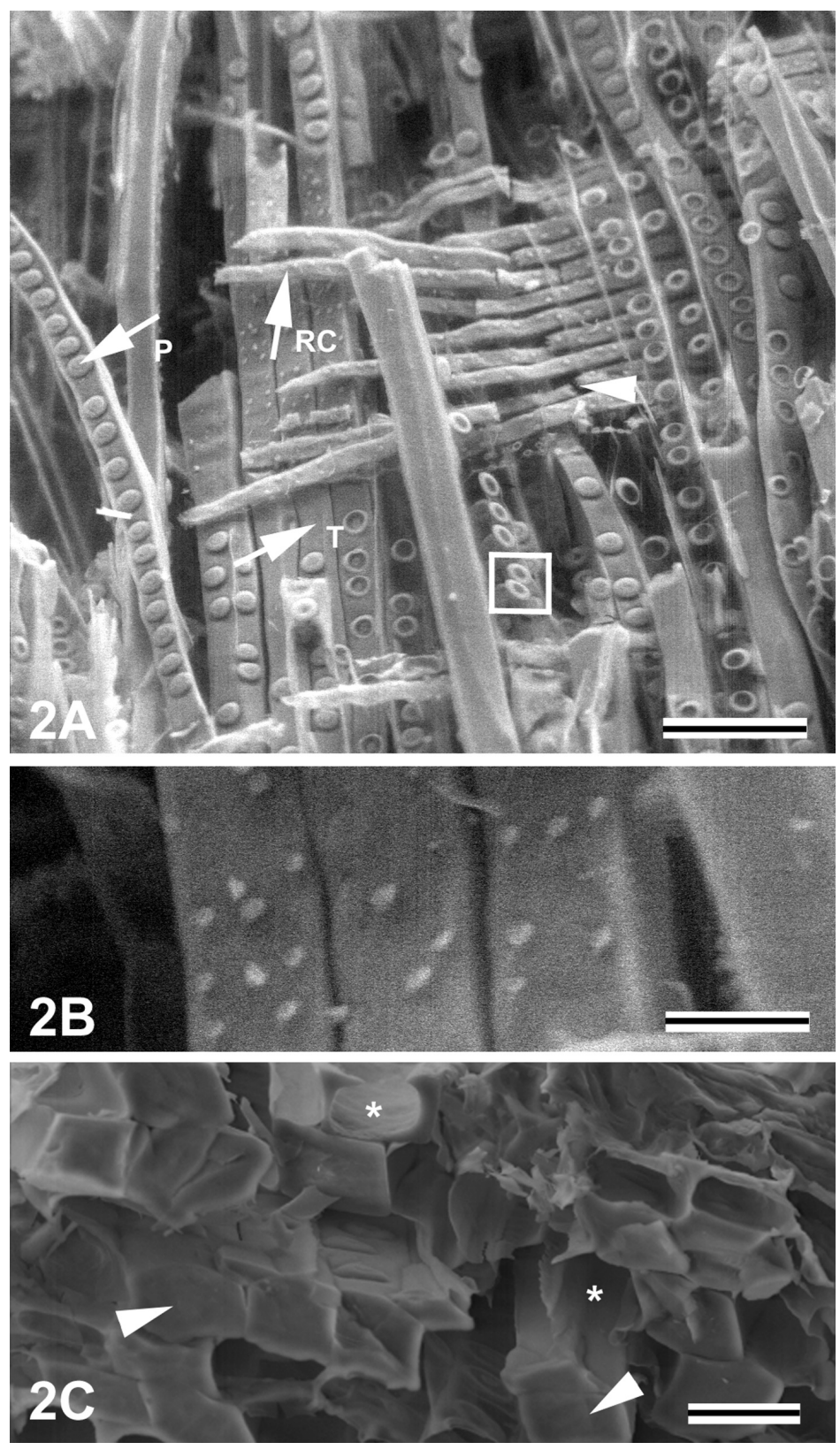

Fig. 2. Silica casts of spruce observed with ESEM. - A: Radial view. Arrows show tracheids (T), ray cells (RC) and pits (P). Artifacts such as released pit units (frame) and fractures (arrowhead) are consequences of the brittleness of the silica material. Scale bar $=50 \mu \mathrm{m}$. $-\mathrm{B}$ : Higher magnification of A shows half-bordered pits on tracheids connecting to ray cells. Scale bar $=15 \mu \mathrm{m}$. - C: Transverse face. Some lumina of the tracheids are filled with silica (arrowheads) whereas other cells are empty and exhibit only cell-wall penetration (asterisks). Scale bar $=25 \mu \mathrm{m}$. 

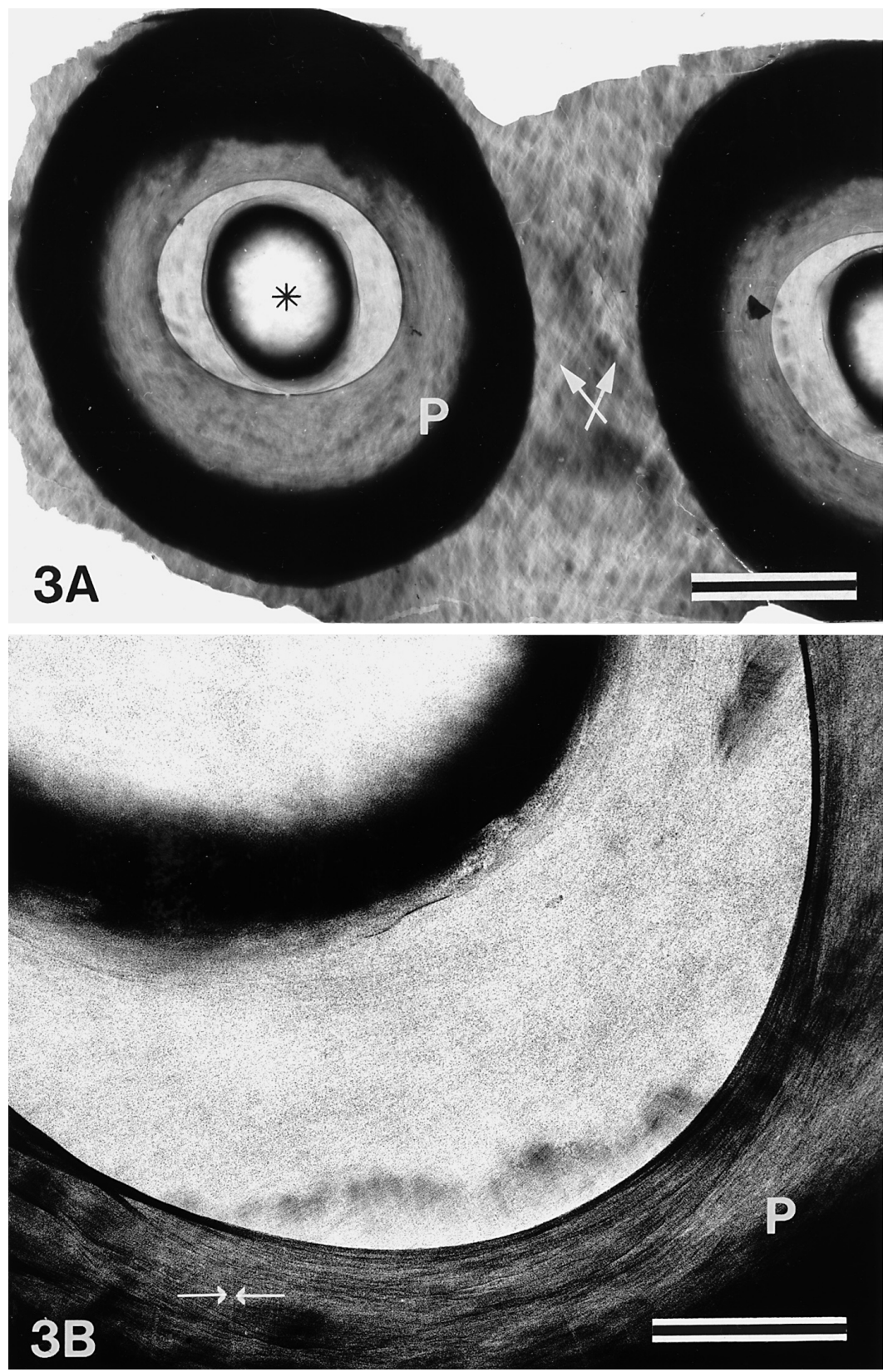

Fig. 3. TEM micrographs of silica casts of spruce. - A: Adjacent bordered pits. Between the pit chambers, a criss-cross pattern of cellulose microfibrils can be seen (arrows). The position of the torus (*) and the pit-chamber wall $(\mathrm{P})$ are indicated. Scale bar $=5 \mu \mathrm{m}$. $-\mathrm{B}$ : Details of a pit membrane. The concentric orientation of cellulose fibrils around the pit-membrane chamber, and cellulose strands of the margo (between the arrows) are visible. The pit-chamber wall is indicated $(\mathrm{P})$. Scale bar $=1 \mu \mathrm{m}$. 
sample resembled that of the untreated wood chip. The dimensions in the fiber directions were roughly maintained whereas shrinkage perpendicular to the fiber axis, amounting to approximately $20-40 \%$, often occurred after calcination. This decrease in macroscopic dimensions can probably be explained by the brittleness of the silica and the incomplete impregnation of some parts of the sample, resulting in collapse during calcination. However, individual tracheids, ray cells, fibers and vessels, as well as smaller structures such as pits and margo strands, were, in contrast to the overall dimensions of the wood chips, not visibly affected by the high-temperature treatment and they retained their original features.

\section{Replicas of spruce wood and pulp}

When the lumen is filled with polysilicic acid, and no cell-wall penetration occurs, a mould of the lumen is obtained, but under the conditions used in this study, polysilicic acid is able to penetrate the cell wall and also to produce positive cast replicas of the cell wall. Figure 2 (A-C) shows ESEM micrographs of silica casts from spruce. The cell walls of tracheids and ray cells are reproduced including pits, both connecting tracheids (i.e. bordered pits) and between tracheids and ray cells (i.e. half-bordered pits). Different degrees of impregnation of the lumina were also noted (Fig. 2C), possibly due to drainage during the drying step leaving only the cell walls silica-loaded.

In the same sample as that in Figure 2, bordered pits were observed by TEM (Fig. $3 \mathrm{~A} \& \mathrm{~B})$. The samples were taken from fragments released from the replica and they were often found to contain pits. These pits display the changes in microfibril angle around the pits reported earlier (Bailey \& Vestal 1937; Imamura \& Harada 1973). In Figure 3A, imprints of cellulose microfibrils can be seen aligned and orientating with the shape of the pits and forming a criss-cross pattern between the two pit chambers. In the TEM micrograph (Fig. 3B), the margo and torus were observed and the strands of the margo (between the arrows) were visible. A fragment of the secondary wall from a spruce kraft pulp is shown in Figure 4. Cell-wall microcavities are represented by the

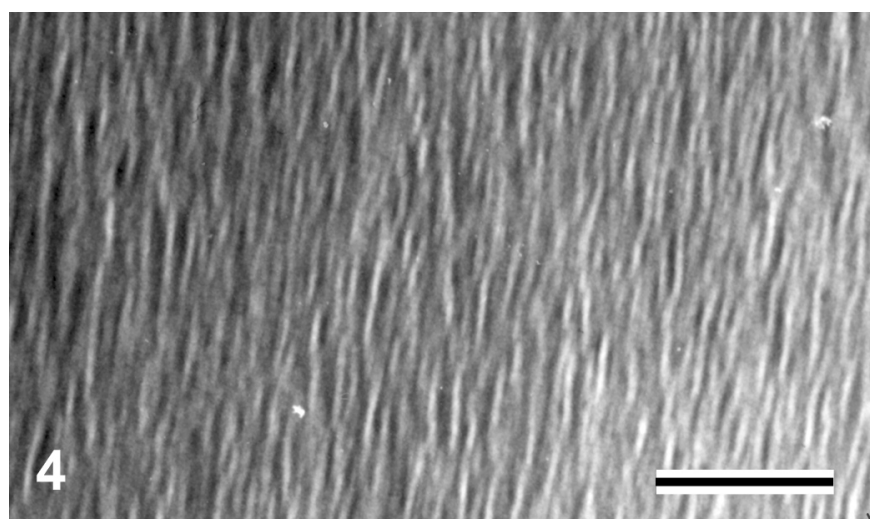

Fig. 4. Silica cast of secondary wall $\left(\mathrm{S}_{2}\right)$ of delignified spruce (residual lignin content $3 \%$ ) observed with TEM. The light-shaded structures indicate cavities originating from the cellulose microfibrils. The width of these structures was about $4 \mathrm{~nm}$. Scale bar $=50 \mathrm{~nm}$. 

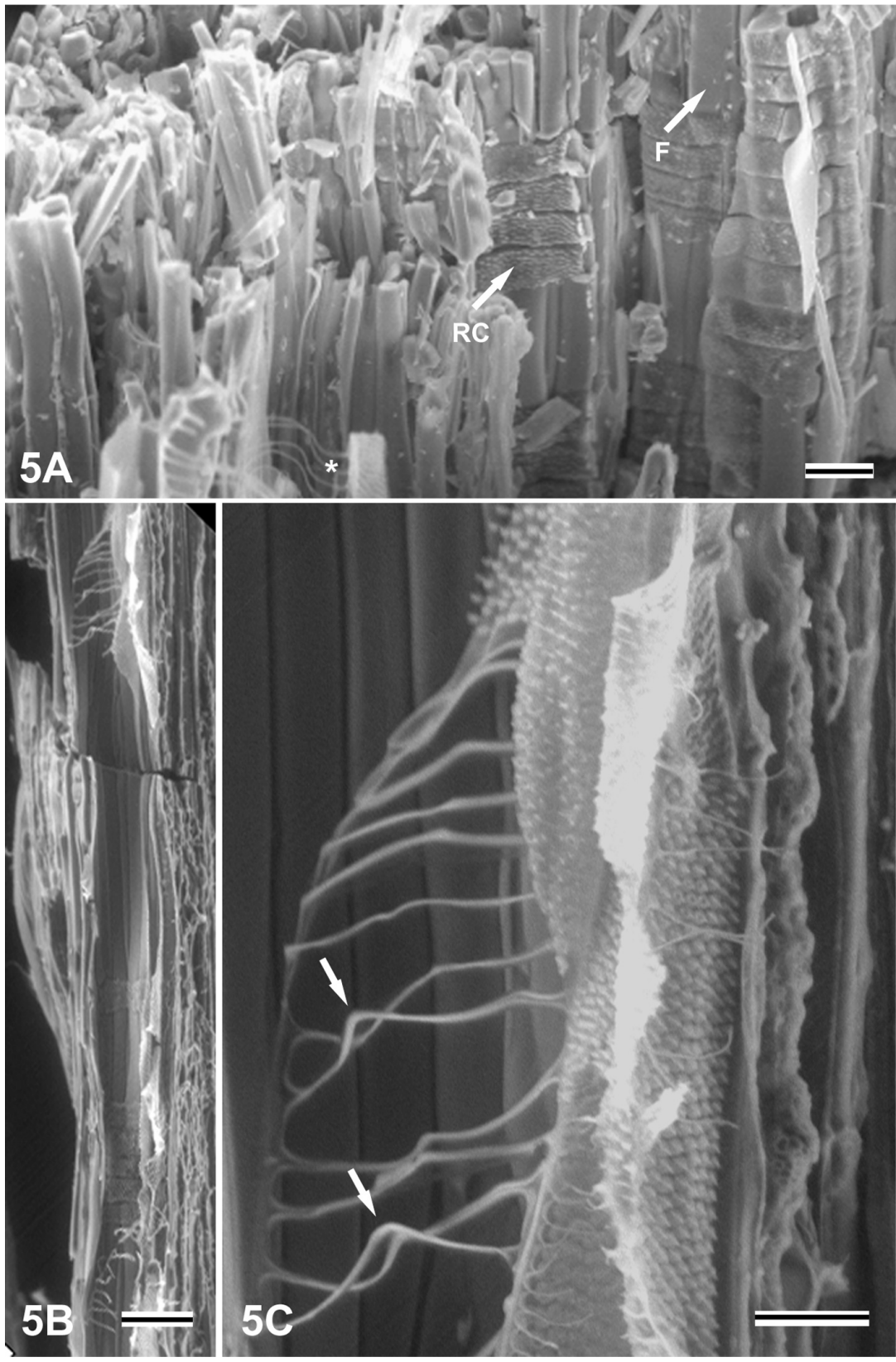

Fig. 5. Silica casts of birch observed with ESEM. - A: Transverse section showing fibers (F) and ray cells $(\mathrm{RC})$. The asterisk indicates scalariform perforations. Scale bar $=25 \mu \mathrm{m}$. $-\mathrm{B}$ : Vessel element with a total length of $0.6 \mathrm{~mm}$. Scale bar $=50 \mu \mathrm{m}$. $-\mathrm{C}$ : Higher magnification of 5B showing a scalariform plate. The bent appearance (arrows) of some of the scalariform bars is probably an artifact, possibly caused by the high-temperature treatment or some mechanical disruption during preparation. Scale bar $=15 \mu \mathrm{m}$. 
dark regions (filled with silica), whereas the light (unfilled) structures, oriented and uniform in size, may originate from the cellulose microfibrils.

The width of these microfibrils (approx. $4 \mathrm{~nm}$ ) agrees with those of earlier reports. Heyn (1977) reported a width of $3.5 \mathrm{~nm}$ based on electron microscopy studies on conventionally heavy-metal stained and plastic embedded cellulose samples, whereas Hult et al. (2000) reported a microfibril width of $3.8 \mathrm{~nm}$ using NMR.

\section{Replicas of birch wood}

Compared to softwoods, hardwoods have a more complex structure. Therefore, to further evaluate the usefulness of the silica-cast replica method for morphological studies on wood, replicas were also made of wood chips of birch. In Figure 5A, vessels, fibers and ray parenchyma cells in birch are shown. The width of the fibers was approximately 15-20 $\mu \mathrm{m}$. The lumen of most of the fibers was filled with silica whereas the vessel lumina were mostly empty. A possible explanation is that vessel lumina, due to their larger diameter, were more easily drained from impregnation liquid during the drying stage prior to calcination. In Figure 5B, a vessel element of about $0.6 \mathrm{~mm}$ in length is shown, and in Figure 5C a scalariform plate. In terms of sample handling and mineralization efficiency, no difference between spruce and birch was observed, and both wood species were reproducibly mineralized.

\section{CONCLUSIONS}

This study has shown that sol-gel mineralized wood replicas can be used for detailed morphological studies on wood, although at the wood-chip level some shrinkage was observed in the radial and tangential planes.

\section{ACKNOWLEDGEMENTS}

This work was carried out within the framework of the Wood Ultrastructure Research Centre (WURC), a competence center at the Swedish University of Agricultural Sciences. Joanna Hornatowska and Owe Lidbrandt are thanked for technical assistance with the ESEM measurements. IRECO is gratefully acknowledged for financial support.

\section{REFERENCES}

André, J.-P. 1998. A study of the vascular organization of bamboos (Poaceae-Bambuseae) using a microcasting method. IAWA J. 19: 265-278.

Bailey, I.W. \& M.R. Vestal. 1937. The orientation of cellulose in the secondary wall of tracheary cells. J. Arnold Arbor. 18: 185-195.

Davis, S. A., S.L. Burkett, N.H. Mendelson \& S. Mann. 1997. Bacterial templating of ordered macrostructures in silica and silica-surfactant mesophases. Nature 385: 420-423.

Dong, A., Y. Wang, Y. Tang, N. Ren, Y. Zhang, Y. Yue \& Z. Gao. 2002. Zeolitic tissue through wood cell templating. Adv. Mater. 14: 926-929.

Drum, R.W. 1968. Silicification of Betula woody tissue in vitro. Science 161: 175-176.

Frey-Wyssling, A. 1937. Röntgenometrische Vermessung der submikroskopischen Räume in Gerüstsubstanzen. Protoplasma 27: 372-411. 
Frey-Wyssling, A. \& K. Mitrakos. 1959. Einlagerung submikroskopischer Metallteilchen in Pflanzenfasern. J. Ultrastruct. Res. 3: 228-233.

Fujii, T. 1993. Application of a resin casting method to wood anatomy of some Japanese Fagaceae species. IAWA J. 14: 273-288.

Fujii, T. \& Y. Hatano. 2000. The LDPE resin-casting method applied to vessel characterisation. IAWA J. 21: 347-359.

Greil, P., T. Lifka \& A. Kaindl. 1998. Biomorphic cellular silicon carbide ceramics from wood: I. Processing and microstructure. J. Eur. Ceram. Soc. 18: 1961-1973.

Hardy, M.R., R.R. Townsend \& Y.C. Lee. 1988. Monosaccharide analysis of glycoconjugates by anion exchange chromatography with pulsed amperometric detection. Anal. Biochem. 170: $54-62$.

Heyn, A.N.J. 1977. The ultrastructure of wood pulp with special reference to the elementary fibril of cellulose. Tappi 60: 159-161.

Hult, E.-L., P.T. Larsson \& T. Iversen. 2000. A comparative CP/MAS ${ }^{13} \mathrm{C}-\mathrm{NMR}$ study of cellulose structure in spruce and kraft pulp. Cellulose 7: 35-55.

Iler, R.K. 1979. The chemistry of silica. John Wiley \& Sons, New York.

Imamura, Y. \& H. Harada. 1973. Electron microscopic study on the development of the bordered pit in coniferous tracheids. Wood Sci. Technol. 7: 189-205.

ISO 302-1981 standard test method. 1998. In: Standards Handbook; paper, board and pulps. International Organization for Standardization, Geneva. ISBN 92-67-10270-2.

Kitin, P., Y. Sano \& R. Funada. 2001. Analysis of cambium and differentiating vessel elements in Kalopanax pictus using resin cast replicas. IAWA J. 22: 15-28.

Li, T.-Q., U. Henriksson \& L. Ödberg. 1993. Determination of pore sizes in wood cellulose fibres by ${ }^{2} \mathrm{H}$ and ${ }^{1} \mathrm{H}$ NMR. Nord. Pulp Paper Res. J. 8: 326-330.

Mann, S., S. L. Burkett, S. A. Davis, C.E. Fowler, N.H. Mendelson, S. D. Sims, D. Walsh \& N.T. Whilton. 1997. Sol-gel synthesis of organized matter. Chem. Mater. 9: 2300-2310.

Monnier, F., F. Schüht, Q. Huo, D. Kumar, D. Margolese, G. D. Maxwell, G. D. Stucky, M. Krishnamurty, P. Petroff, A. Firouzi, M. Janicke \& B.F. Chmelka. 1993. Cooperative formation of inorganic-organic interfaces in the synthesis of silicate mesostructures. Science 261: $1299-1303$.

Ogasawara, W., W. Shenton, S. A. Davis \& S. Mann. 2000. Template mineralization of ordered macroporous chitin-silica composites using a cuttlebone-derived organic matrix. Chem. Mater. 13: 2835-2837.

Ota, T., M. Takahishi, T. Hibi, M. Ozawa, S. Suzuki, Y. Hikichi \& H. Suzuki. 1995. Biomimetic process for producing SiC “wood”. J. Amer. Ceram. Soc. 78: 3409-3411.

Saka, S., M. Sasaki \& M. Tanahashi. 1992. Wood-inorganic composites prepared by sol-gel processing I. Wood-inorganic composites with porous structure. Mokuzai Gakkaishi 38: 1043-1049.

Scallan, A.M. 1987. On non-solvent water in cellulosic fibres as determined by salt exclusion. Cellulose Chem. Technol. 21: 215-223.

Shin, Y., J. Liu, J.H. Chang, Z. Nie \& G. J. Exarhos. 2001. Hierarchically ordered ceramics through surfactant-templated sol-gel mineralization of biological cellular structures. Adv. Mater. 13: 728-732.

Stone, J.E. \& A.M. Scallan. 1968. The effect of component removal upon the porous structure of the cell wall of wood. III. A comparison between the sulphite and kraft processes. Pulp Pap. Mag. Can. 69: 69-74.

Theander, O. \& E. A. Westerlund. 1986. Studies on dietary fiber. 3. Improved procedures for analysis of dietary fiber. J. Agric. Food Chem. 34: 330-336. 